\title{
Internet of Things (IoT) Technologies for Empowering E-Education in Digital campuses of Smart Cities
}

\author{
Amira Hassan Abed \\ Dept. of Information Systems Center, \\ Egyptian Organization for Standardization \& Quality, Egypt \\ mirahassan61286@gmail.com
}

ABSTRACT-

This article centers around the exploration related to the e-learning in the smart cities. The recent innovation, for example, Internet of Things (IoT) is quickly grown in the computerized life. Formation of the intelligent urban communities is developing with the idea of the IoT in the same time. E-residents as the fundamental component play an imperative part in building the keen urban communities. It is undeniable that another type of the resident in the smart cities can assume a fundamental part in case he/she gets satisfactory e-learning. In the computerized life, the IoT grounds in the intelligent urban communities are focused on the enhancement of the e-Leaning part by utilizing advanced communications and methods. Our work here centers around the requirement of embracing IoT techniques in campuses of intelligent cities, as well as supporting the theoretical analysis about the anticipated benefits of the smart learning and its application in the brilliant communities in a definite discussion.

Keywords- E-Leaning; E-education; Digital campuses; Internet of Things (IoT); smart cities.

\section{INTRODUCTION}

$\mathrm{I}_{\mathrm{OT}}$ is a pervasive innovation that gives correspondence and joint effort between the entities. IoT networks is increasing in numbers of linked entities connected by it which affecting various parts of our life like the learning and teaching systems [1]. IoT networks and technologies were first introduced in our world in 1999 by Kevin Ashton during his working in the Auto-ID lab at MIT, expressing the innovations which motivated IoT, for example, Radio Frequency Identity device (RFID) and Wireless sensor networks (WSNs) [1]. In light of the essential thought of IoT, all entities which get an IP address can actually want to cooperate with one another truly and basically [2]. The primary Internet of things construction is depended on the information detected by sensors, labels or actuators and transferring it via a passage to a cloud computing framework. The IoT communication incorporates Machine-to-Machine, thingto Machine or thing to thing.

The scope of uses created through IoT area is from a simple systems in home to the high level a medical procedure frameworks. IoT incorporates numerous parts of the human's existence like shrewd urban areas, intelligent organizations and intelligent energy utilization, and so forth. Learning, Teaching and Training are quite possibly the most noticeable individual activity which IoT can impact on, changing the state of Learning to an inventive design [3].

Moderately, the IoT is a pervasive marvel which upholds innovativeness in a lot of areas. The space of Learning (eschooling, e-Learning, e- teaching) is a critical area of these areas. As IoT able to be integrated with information systems and information technology advances, it would support an immense assortment of the e-teaching advances and facilities that enables it to enhance the eventual fate of the Learning and teaching frameworks. The intelligent Learning would be outfitted with intelligent tools and techniques. learners and instructors confirm their legitimacy of as clients accessing via face-prints, eyeprints, fingerprints and, RFID ID Card checking to go into to the actual rooms or admittance to the programmed framework the board of the organization, university, campus, or education center. The smart IoT rooms incorporate the sensors to approve the instructors and learners passing. The intelligent whiteboards and work areas could be outfitted with the RFID or WSN gadgets which able to efficiently distinguish the clients. learners and instructors would be able to cooperate with one another commonly in the intelligent IoT classrooms.

IoT could give the productive association between a lot of smart entities actually and basically. This permits the learning items, like learners, associating - electronically-to the tutorials, libraries, instructional materials, evaluations, and instructive chats and regulatory assignments in a productive way (viable e-education) in an enormous size virtual classes. Besides, via this type of e- education, every teaching assignments and exercises would really be settled as entities. Likewise, e-education, begun in the 80 's, alludes as enabling electronic apparatuses, equipments, softwares, and online operations in the education framework. All things considered, the growth of innovation development and specialized apparatuses have empowered the web based teaching through the huge education means (IoT).

The IoT permits the development of intelligent education systems through coordinating various items via meddling them in the intelligent teaching and education systems. 
The customary electronic teaching and education, as an advanced procedure, could support a huge virtual entrance for end-users, and yet there are a few constraints. The topographical places, face to face correspondence among entities, and viable participation among virtual and actual specialists should be the principle impediments in elearning. Applying intelligent entities in the smart education platforms is a solution to overcome the reported problems.

IoT is the principle supplier of keen specialists for eTeaching biological systems [4]. IoT could introduce two fundamental components within the conventional eTeaching which are the intelligent concept and item cooperation (entity to entity, machine to machine). IoT give a gigantic stage to students and educators with a various assortment of remotely Teaching gadgets and items. advanced connection among entities will produce an incredible number of cooperation frameworks. As recently referenced, the extent of the IoT systems is reached out from the straightforward intelligent houses, intelligent associated urban areas, and metropolitan management frameworks the board to the confounded medical services frameworks.

IoT includes all large scale individuals existence exercises as well as activities, for example, e-teaching which is one of the new focal points of the metropolitan intelligent city scientists. Utilizing the correspondence Innovation by IoT is changed over as the most fundamental elements in planning the intelligent urban communities. like a smart tool, it permits access from an online- teaching framework to a shared interactive model to enhance information and knowledge exchange on the e-resident fostering their abilities in the e-local area and shaping the onlineteaching computerized society [4]. Metropolitan IoT is intended to help the savvy city idea, to exploit the most progressive ITC advancements.

One of different measurements for the keen cities is that the urban communities can be more brilliant by consolidating the assorted trend setting innovations. Joining the IoT into the Data and correspondence advancements can help in further developing the additional worth administrations and instructive exercises with the reason for organization measure improvement. Keen Urban areas can join different information and technology communications and IoT innovations to diminish their natural effect and proposition better eeducative stage and administrations [1]. our contribution here investigates a few mechanical benefits of IoT on Eteaching framework in the brilliant urban communities which would be introduced in the accompanying sections.

\section{Internet of Things aided intelligent Teaching}

As referenced previously, teaching considers the fundamental ideas in the people's exercises which, is integration of the new innovation and advancement difficulties like IoT. A Fundamental IoT framework Engineering is uncovered in Figure 1 in which the essential IoT design is separated into three levels: applications, communication and insight levels.

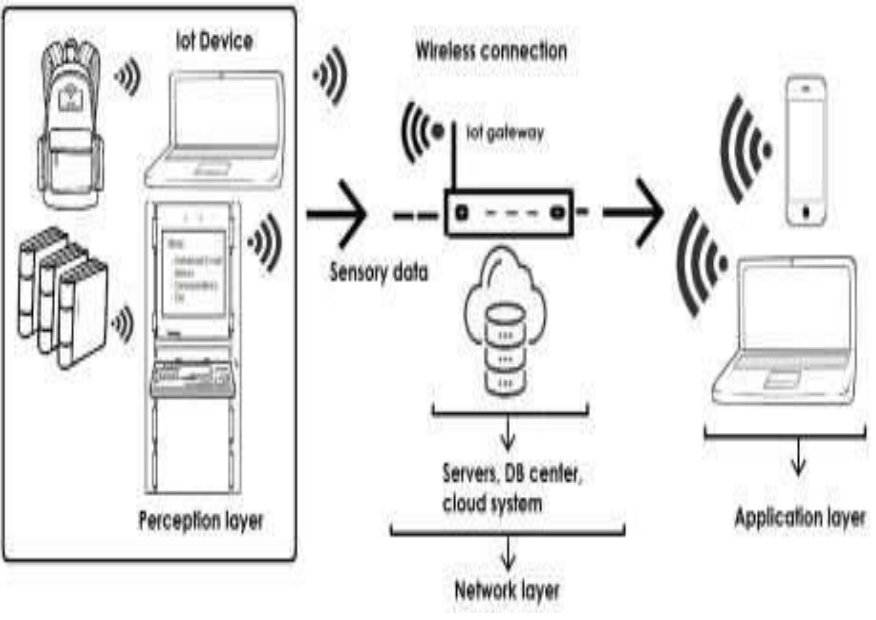

Fig. 1: the Basic IoT Architecture

The applications level offers types of assistance to client applications utilizing an user- front end. The communication level is accountable for giving association among hubs and access point. The access point is a delegate between the applications and insight levels, to acquire the information detected from the sensor hubs in the insight level and send data to a cloud/fog computing framework. In addition, the insight level incorporates the actual entities or sensors that can detect an occasion or item activity. A little detecting framework in that level is liable for detecting (RFID, WSN) and putting away the information detected. Figure 2 is exhibited an essential IoT construction in which IoT gadgets identify the occasions, objects or any information in the insight level. The sensor information would be shipped off the access points, put away in a cloud framework. The information than are preparing to be able to utilize in decisions making.

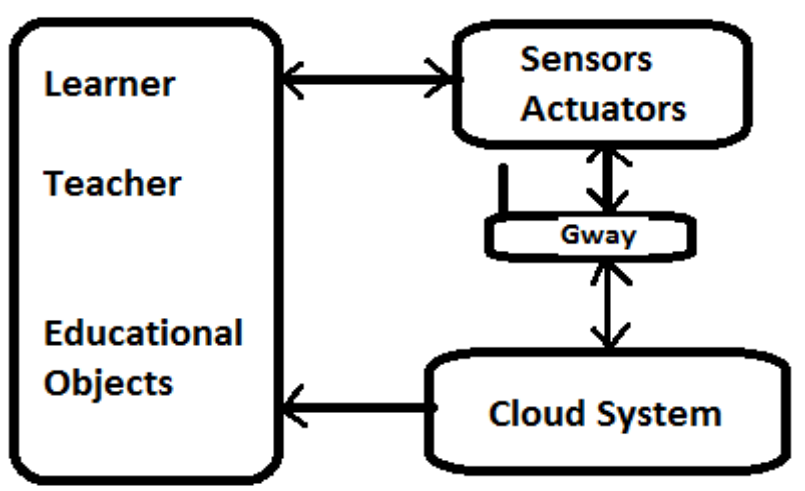

Figure 2. IoT aided E-Learning

Consistently more intelligent entities and things are custom-made to the few situations and are turning out to be more pervasive in various purposes of learning, teaching and training. Among the shrewd administrations and activities upheld via the growing advancements like IoT, intelligent Learning is one of the principle components in execution of IoT intelligent urban communities, which are empowered by online teaching and digitalization (Figure 3). This grouping is brought about numerous examinations by specialists. Figure 3 , is 
perhaps identify the IoT brilliant communities applications that teaching and training is one of the primary components of a smart city executed and developed based mainly on IoT. IoT is enhancing the customary teaching components like organizations, colleges, campus, learners and different components to the intelligent onlineTraining, online -campus, online -College, and online learners. Intelligent teaching is a issue in the construction of keen communities that a few academics and scholars have focused on [1], [2], [3], [5] most teaching organizations are not associated or divide their data among themselves.

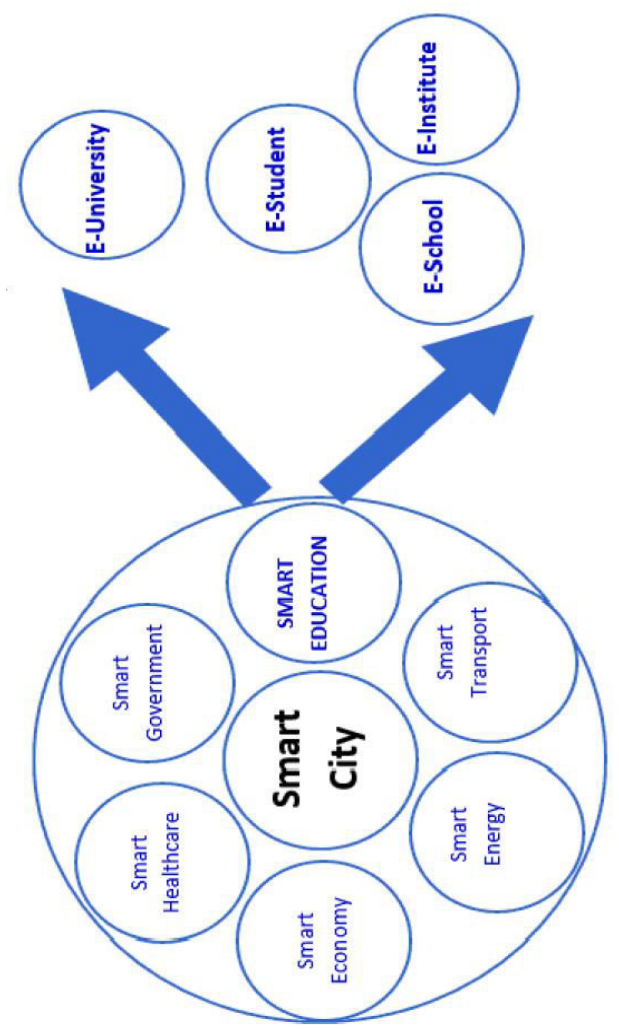

Fig.3: IoT Smart city applications

Versatile advanced communication and information technology capabilities, for example, IoT are needed to satisfy this issue, enhancing the customary teaching and training framework to the current framework through the new innovation like Web of things (WoT).

The IoT utilization in the teaching environment incites a lot of associations and links among instructive items producing data in immense amounts. Including the IoT in the teaching and training areas likewise, allows many associations and links between various items, for example, students and educators. Moderately, new chances of developments are allowed to the training and teaching platforms to further develop the education system empowering big association among entities which give many intelligent capabilities [6]. As Figure 4 presents, IoT empowers the networking innovation and Figure 5 shows IoT advancements in the teaching and training in digital schools. The thoughts of intelligent urban areas and its teaching substances, for example, brilliant schools is a famous idea and utilization of IoT in the teaching and training frameworks [7].

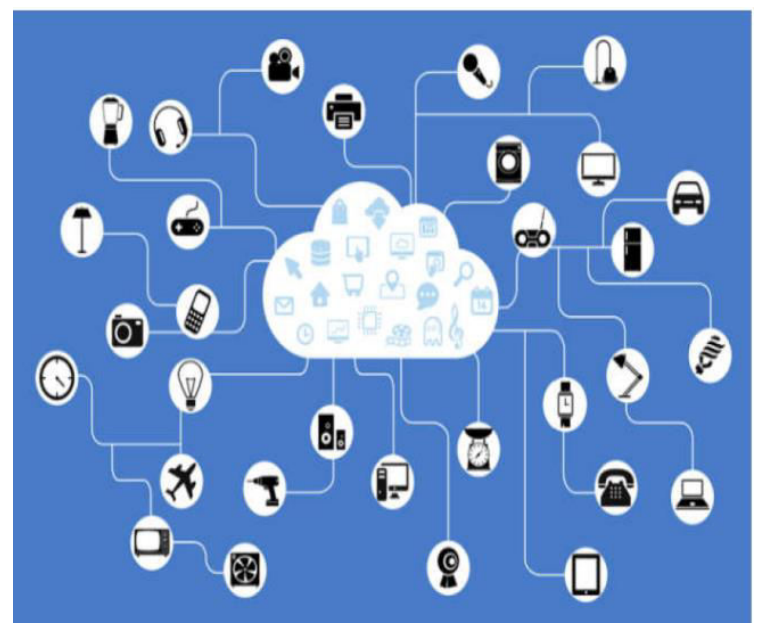

Fig. 4: IoT empower Communications

\section{a) IoT Innovation empower E-learning}

These days, the new Internet innovations were enhanced the learning platforms and models. The possibility of the pervasive innovation enabled many advantages like the chance of instructing and training whenever, any spot where the students and educators located. It implies an incredible level of openness which enabled Internet and its innovations to enhance and empower the conventional learning and training frameworks to the advanced ideas in the learning areas. Trough utilizing the IoT applications in online- learning practices and exercises, the student will cooperate with the teacher, distantly performing every task, electronic evaluations and receiving the outcomes in a continuous mode.

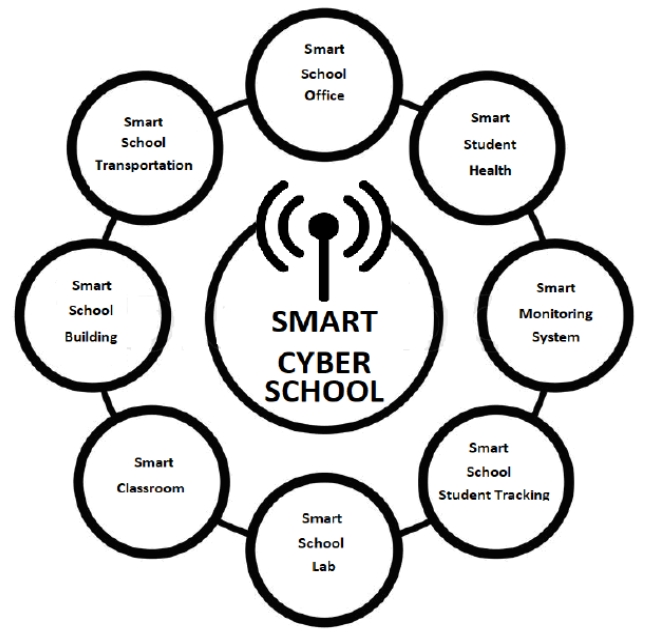

Fig 5: E-School with IoT [6]

The two part learner and educator, presently don't need to complete the physically tasks. All things being equal, they can focus on the learning errands which are the chief item 
in the education proficiency. They could utilize the Internet innovations like WSN and Cloud framework, to gather information identified with student productivity; moreover, instructors could utilize to upgrade execution of every instructive entities [8]. IoT as a new predominant innovation is affecting day to day life [9]. It propose a lot of benefits in different sections identified with the learning plans. some these benefits are chosen and in the accompanying sections and the given advantages will be talked about.

\section{b) Remote admittance to LAB}

One of the primary provisions which IoT gives is association among entities in reality and virtual space. As Figure 6 presents, a client can interface with the labs broadly and worldwide and approach the lab items through the Web. The design of IoT makes conceivable a client to distantly interface with the techniques and carry out the tests, gather and get information for additional investigation or tasks and exercises. Additionally the learner or instructor able to carry out the planned experiment essentially by getting to the virtual mode labs distantly.

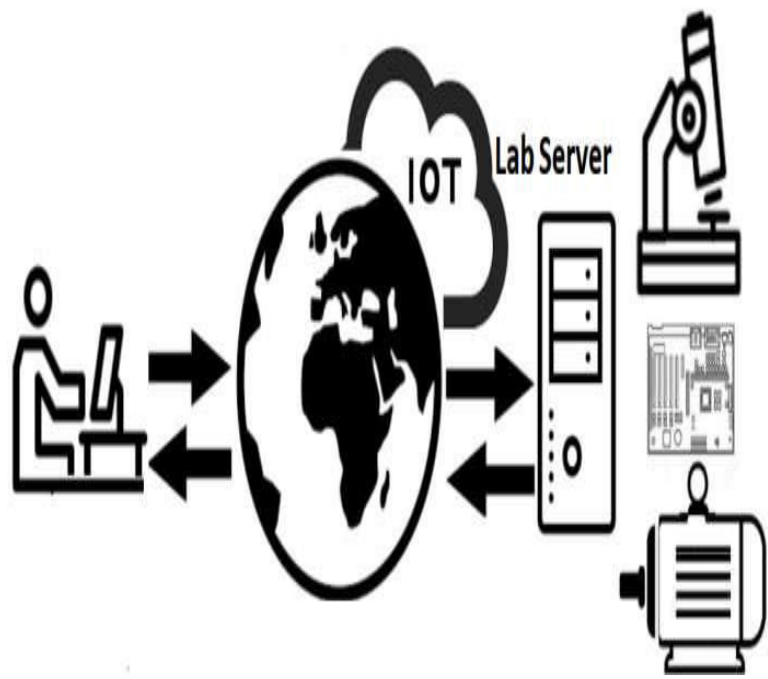

Fig. 6: IoT Remotely Access to Lab

\section{c) Continuous accessibility to Worldwide Libraries}

One more design given based on IoT is an overall internetworking of the libraries. IoT, using the networking association grants passing to the reality or online libraries platforms. Online worldwide association with the libraries in every locations enable the worldwide access conceivable to trainers, scientists or educators. By utilizing the brilliant advancements, for example, Web of things the knowledge element of IoT introduced into the models, operations, and empowering the platform to become smarter and successful [10]. Thus, IoT empowers intelligent pass to the worldwide libraries applications. The student in this manner able to pass $7 / 24$ [8] to the a lot of college libraries to gain passing to these electronic facilities. The IoT and the advances which help it, assemble countless worldwide connecting between books assortments and public libraries all throughout the planet.
This permits the clients to interface with the goliath book depository and knowledge banks on the web.

\section{d) Intelligent Team-Works and Cooperation}

In light of the E-education platforms, the cooperation application is ridiculously needed in these sorts of the foundation [9]. The electronic world that aided IoT, just as the successful association and correspondence among various entities, permits developing an intelligent application in various phases of the learning systems. The advanced networking capabilities are the fundamental in settings of cooperation application for educative foundations. In light of the proficient connections among reality and virtual entities just as networking tools that is given through IoT, a significant level of links and cooperations are produced [11].

Actually, IoT support a huge size of cooperation application, for example, the brilliant advancements of WSN support it and allow the appropriate and compelling links among virtual and actual items. It is needed to recall that all cooperation frameworks are not intelligent. In any case, utilizing the new advancements which help IoT, the genuine idea of cooperation in the e-teaching would enhance the distinctive intelligent cooperation systems. In a intelligent coordinated climate, expounded via the IoT, the clients complete a more works smartly through eteaching application. They can plan a superior timetable of their exercises in a intelligent cooperation system. Brilliant cooperation frameworks likewise can energize a more proficient collaboration arranging [12]. IoT owns the facilities of giving an immense cooperation stage by associating a lot of items internationally. It can empower group working in a colossal size that enables creating the extremely huge venture bunches which allow collaborations between the team and thoughts. The students, too the teachers, have abilities to operate within a worldwide foundation or inside the public geological areas. By and large, one might say that a huge enhancement is unsurprising and projected by utilizing IoT devices, platforms and advances.

\section{e) Electronic independent Learning}

The main point in the independent Learning is to urge the students to concentrate on materials and not depend on instructor intercession. so, the understudies are self inspired to achieve their tasks separately [13]. As prior to seeming IoT the students couldn't be communicate with different learning entities, but presently via electronically live, IoT can help the human in its investigating information autonomously. How about we expect a straightforward situation in the college of a university wherein some accessible remote PCs are situated around the university. The student that has an inquiry or fosters a question can connect with the PC and achieve the request. The client after passing the validation measure by an actual checking (authentication Card) able to acquire all data of his requirement by gaining admittance to access the device. Thusly, student can gain admittance to countless instructive assets anyplace, whenever, doing tasks, gathering materials, sending and getting tasks to the 
educators. IoT permits interfacing anything to any things, anyplace and whenever. learners can interface with every smart libraries as well as smart labs and performing tests, recovering any information that they want by enrolling their portable of actual validation. They can get arranged tasks, doing evaluation, sending the works and getting the tests consequences,

\section{i. An itemized benefits rundown of E-learning based IoT}

- IoT can interface the Teaching framework to the students and instructors remotely that allowing the students to pass for learning materials. The students can carry out their trials interfacing with the high level labs all throughout the planet. They can browse to discover numerous answers for their inquiries and questions by connecting to enormous amounts of data that are put away anyplace and whenever that resulted in further develop the e-learning measure.

- By fostering another plan of IP address (IPv6), practically all gadgets that can acquire an IP can associate with one another and to the physical or virtual universe. This can produce huge measures of information and cooperation between objects. Understudies and educators as the instructive items can communicate in a constant. Human, robots and programming instructors will help understudies distantly, from anyplace and whenever. They can answer all inquiries that have consumed the students' psyches, by doing on the web appraisal and giving related outcomes. It is extremely certain that this marvel has a positive effect over more slender execution.

- IoT, basically, eliminates the presence electronic dividers, time constraints and different hindrances among students and enormous volume of assets like experienced instructors, consequences of explores and arrangements, and progressed lab devices. IoT alongside its upheld innovations works with this association. As, those limitations are wiped out, the speed of admittance to the necessary data is expanded basically. Understudies or educators can reach to e-data that they need right away or minutes.

- IoT shrewd urban areas can give the customized elearning stages that are adjusted to the e-understudies' requirements separately. Also, IoT keen urban areas work with the incorporation of the e-residents into the e-local area. It can build the e-student contribution during the time spent the learning.

- IoT is changing the presentation of the genuine Elearning instruments or Medias like remote associations, security (RFID validation) and measurement of assets (cloud frameworks)

- intelligent cities based on utilizing the IoT innovation can give a powerful and cooperating e-learning or eteaching stage to e-individuals who can work together and carry collaboration to encounter sharing, capability, new models of the e-business and that are required for maintainability and upkeep of the city. IoT E-learning stage can give numerous chances to shrewd city networks to partake in the improvement of brilliant urban communities by redesigning their ability through information and instruction moving.

- An accomplished local area will be compromised to the request, law, and cooperation, usefulness of a city and life quality to the residents. These provisions can be accomplished under the structure of the shrewd urban areas.

In rundown, "constructing a savvy city implies prompting shrewd e-learning". Appling IoT e-learning in the shrewd refers to grants the e-resident to be hyper-associated and imaginative with high grade of support and joint effort in the learning system and different choices locally. IoT execution in the shrewd urban areas guarantees a critical impact on the e-learning measures by offering full admittance to the instructive assets of the e-local area, electronically, through a concentrated coordinated framework in a savvy way. Taking everything into account, the hypothetical review shows that the proficiency and effect of IoT in the executed e-schooling and e-learning measure in the savvy urban communities is unsurprising, quantifiable and couldn't be disregarded. Hyper-availability between objects, high grade of openness, adaptability and reconciliation of the correspondence organizations (RFID and WSNs) are properties of the IoT [15] which can strengthen the productivity of e-learning approach in the "intelligent societies" like savvy urban areas. They may be considered as the significant instruments which can uphold IoT-based learning framework which regardless of the current difficulties is making elective effective techniques in the e-instruction environment of the intelligent urban communities in the nearby future. In view of this reality, the future work will be centered around the current elearning approaches and similarity of them in the keen urban areas.

\section{CONCLUSION}

In this work a detailed analysis of the IoT technologies empowering education system in smart cities is investigated. IoT is changing the plan of real education framework. IoT gives an extremely effective correspondence between entities remotely. Likewise, it makes a potential associations between the actual world and the Web which before was not achievable. IoT empowers the worldwide association of various, universities, labs, libraries, elements, individuals, businesses, organizations, offices situated all throughout the planet to the actual entities. A comprehensive discussion was presented to concentrate on the principle advantages of the IoT on the smart education and teaching in the keen communities. 


\section{REFERENCES}

1. Amira Hassan. Mona Nasr, \& Walaa Saber "The Future of Internet of Things for Anomalies Detection using Thermography", International Journal of Advanced Networking and Applications (IJANA), Volume 11 Issue 1, pp. Pages: $4142-4149$ (2019).

2. Parashar R., Khan A. and Neha J. 2020. "A Survey: The Internet of Things", International Journal of Technical,Vol. 4, Issue 3, (May-June, 2016), pp. 251 257.

3. Gómez J. 2020 "Interaction system based on internet of things as support for education." Procedia Computer Science 21, pp: 132- 139.

4. Moreno-Cano V., Terroso-Saenz F., and SkarmetaGómez F. "Big data for IoT services in smart cities", In Internet of Things (WF-IoT), 2019 IEEE 2nd World Forum on. IEEE, 2019.

5. Namiot D. 2019 "On Internet of Things and Smart Cities educational courses." International Journal of Open Information Technologies vol. 4, no.5, pp. 26-38.

6. Marquez J., Villanueva J., Solarte Z. and Garcia A. 2021. "IoT in Education: Integration of Objects with Virtual Academic Communities," In: New Advances in Information Systems and Technologies. Advances in Intelligent Systems and Computing, vol 444. Springer, Cham, pp: 201-212.

7. Liu D., Huang R. and Wosinski M. 2018."Smart Learning in Smart Cities," Publisher Springer Singapore, ISBN 978- 981-10-4343-7, DOI :10.1007/978-981-10-4343-7,first Edition , 232 pages.

8. Bayani M. and Vílchez E. 2020. "Predictable Influence of IoT (Internet of Things) in the Higher Education", International Journal of Information and Education Technology vol. 7, no. 12, pp: 914-920.

9. Bayani M., Segura A., Saenz J. and Mora B. 2019.“ Internet of Things Simulation Tools: Proposing Educational Components," SIMUL, Greece, Athens, The $9^{\mathrm{TH}}$ International Conference on Advances in System Simulation, IARIA Conference, pp. 57-63.

10.del Blanco A., Serrano A., Freire M., and MartinezOrtiz I. "E-Learning Standards and Learning Analytics: can data Collection be Improved by Using Standard Data Models?", IEEE Global Engineering Education Conference, Berlin, Germany, pp. 1255-1261, March 2019.

11. Caviglione L., Coccoli M., Grosso A. "A Framework for the Delivery of Contents in RFID-driven Smart Environments", in Proc. of the IEEE International
Conference on RFID-Technologies and Applications, Sitges, Spain, pp. 45-49, Sept. 2021.

12. Soliman M. and Elsaadany A. 2019. "Smart Immersive Education for Smart Cities with Support via Intelligent Pedagogical Agents," 2019 IEEE 39th International Convention on Information and Communication Technology, Electronics and Microelectronics (MIPRO), 28 July, 10.1109/MIPRO.2019.7522247.

13. Dagger D., O'Connor A. and Lawless S. "Serviceoriented e-Learning Platforms: from Monolithic Systems to Flexible Services", IEEE Internet Computing, Vol. 11, No. 3, pp. 28-35, 2007.

14. Amira H., Mona N., \& Basant S. "The Principle Internet of Things (IoT) Security Techniques Framework Based on Seven Levels IoT's Reference Model" Proceedings of Internet of ThingsApplications and Future ITAF 2019. Springer publisher, Part of the Lecture Notes in Networks and Systems book series (LNNS, volume 114). 